\title{
What are the possibilities of machine learning techniques on the mechanical characterization of biological tissues?
}

\section{Opinion}

The experimental study of the mechanical properties of biological tissues is of paramount importance. A good knowledge of the mechanical response of biological materials (like tissues or organs) is needed as a source of information to be introduced into computational models that can serve to correctly reproduce the associated mechanical behavior. Classical engineering testing has been applied to biological materials ${ }^{1-3}$ to obtain their properties. Simple tension, planar biaxial and inflation tests are considered the main techniques for the measurement of the mechanical response of blood vessels. The most resorted one, regarding its simplicity and versatility, is the uniaxial test, with particular application to soft biological tissues. ${ }^{4-7}$ This technique also presents the feature of being applicable to very small samples. A common practice in the field of mathematical modelling or computational simulation is the use of experimental data to estimate different material model parameters, resorting for that purpose to a strain energy function (SEF), all included in the continuum theory of large deformation hyper-elasticity. The constitutive modelling of soft biological tissues has recently constituted a very active field of research. ${ }^{8}$ These materials have commonly been modelled as hyperelastic continua embedded into continuum mechanical formulations. In this line, one of the main tasks considers the determination of appropriate strain energy density functions, from which local mechanical quantities are obtained. Several constitutive laws have been proposed for soft tissue modelling. ${ }^{1,9-11}$, which may be suitable depending on the kind of soft biological tissue at stake. Holzapfel et al. ${ }^{12,13}$ proposed the most common SEFs for modelling the behavior of blood vessels accounting for two preferred directions, incorporating fiber dispersion with respect to the deterministic preferred orientation direction, and the work presented by Gasser et al. ${ }^{14}$ which includes microstructural information in the model by means of the assumption of a fiber orientation distribution function.

Constant search for effective solutions to the problem of the parameter fitting of soft biological tissues has been put forward by Cilla et al. ${ }^{15}$ proposing the use of machine learning techniques (MLTs) among which are: support vector machines (SVMs), bagged or bootstrap-aggregated decision trees (BDTs) and artificial neural networks (ANNs). Machine learning techniques consider algorithms able to learn and make predictions from data. Complex algorithms, which can be trained to reproduce the behavior of a model, ${ }^{16,17}$ represent the main feature. MLT's are quite multidisciplinary, with applicability to many different areas, such as electronics, ${ }^{18}$ industry, ${ }^{19}$ earth sciences, ${ }^{20,21}$ space science $^{22}$ or language ${ }^{23}$ among many others. These techniques have also been applied to different clinical applications like the assessment of electrocardiograms, diagnosis of breast cancer, prediction of femur loads, or optimization of hip implant geometries. ${ }^{24-28}$ They have also been used for treating cardiovascular diseases. ${ }^{29-33}$ MLT's can be proposed as good candidates to identify different material model parameters, and we strongly believe that the use of these mathematical tools could successfully help to improve
Volume 6 Issue I - 2020

\author{
Martínez J,' Pérez-Rey I, ${ }^{2}$ Cilla M $^{3}$ \\ 'Department of Applied Mathematics I, University of Vigo, Spain \\ ${ }^{2}$ Department of Natural Resources and Environmental \\ Engineering, University of Vigo, Spain \\ ${ }^{3}$ Centro Universitario de la Defensa de Zaragoza, Spain
}

Correspondence: Dr. Javier Martínez Torres, Department of Applied Mathematics I, University of Vigo, Escuela de Ingeniería de Telecomunicación, Campus de Vigo 36310, Spain, Tel +34986 812 247, Email javmartnez@uvigo.es

Received: November 12, 2019 | Published: January 22, 2020

the characterization of soft biological tissues. Moreover, the use of MLTs also presents certain advantage in terms of computational costs, reducing computation time in comparison to gradient-base methods, where this time becomes indefinite, searching for an appropriate initial seed. Therefore, MLTs can be likely positioned as good candidates to replace gradient optimization methods that lead to fit the material parameters in the experimental testing of samples of soft biological tissues. $^{34}$

\section{Funding details}

None

\section{Acknowledgments}

None.

\section{Conflict of interests}

Authors declare that there is no conflict of interest.

\section{References}

1. Fung YC, Fronek K, Patitucci P. Pseudoelasticity of arteries and the choice of its mathematical expression. Am J Physiol. 1979; 237:620-631.

2. Fung YC. Biomechanics. Mechanical Properties of Living Tissues. New York. Springer-Verlag; 1990.

3. Humphrey JD. Stress, strain, and mechanotransduction in cells. ASME J Biomech Eng. 2001;123(6):638-641.

4. Hayashi K, Washizu T. Tsushima N, Kiraly R J, Nose Y. Mechanical properties of aortas and pulmonary arteries of calves implanted with cardiac prostheses. J Biomech. 1981;14(3):173-182.

5. Hayashi K, Imai H. Tensile property of atheromatous plaque and an analysis of stress in atherosclerotic wall. J Biomech. 1997;30:573-579.

6. Schulze-Bauer CAJ, Mörth C, Holzapfel GA. Passive biaxial mechanical response of aged human iliac arteries. ASME J Biomech Eng. 2003;125:395-406. 
7. Holzapfel GA, Stadler M, Gasser CT. Changes in the mechanical environment of stenotic arteries during interaction with stents: computational assessment of parametric stent designs. ASME J Biomech Eng. 2005a;127:166-180.

8. Ogden RW. Nonlinear elasticity, anisotropy, material stability and residual stresses in soft tissues. Biomech Soft Tissue Cardiovasc Syst. CISM Courses Lect. 2003;441:65-108.

9. Demiray H. A note on the elasticity of soft biological tissues. J Biomech 1972;5:309-311.

10. Humphrey JD, Yin FC. A new constitutive formulation for characterizing the mechanical behavior of soft tissues. Biophys J. 1987; 53(4):564-570.

11. Weiss JA, Maker BN, Govindjee S. Finite element implementation of incompressible, transversely isotropic hyperelasticity. Comput Methods Appl Mech Eng. 1996;135:107-128.

12. Holzapfel GA, Gasser CT, Sommer G, et al. Determination of the layerspecific mechanical properties of human coronary arteries with nonatherosclerotic intimal thickening, and related constitutive modelling. Am J Physiol-Heart Circulatory Physiol. 2005b; 289:2048-2058.

13. Holzapfel GA, Gasser TC, Ogden RW. A new constitutive framework for arterial wall mechanics and a comparative study of material models. J Elast. 2000;61:1-48.

14. Gasser TC, Ogden RW, Holzapfel GA. Hyperelastic modelling of arterial layers with distributed collagen fibre orientations. $J R$ Soc Interface. 2006;3:15-35.

15. Cilla M, Pérez-Rey I, Martínez MA, et al. On the use of machine learning techniques for the mechanical characterization of soft biological tissues. Int J Numer Meth Biomed Eng. 2018:e3121.

16. McCulloch WS, Pitts WS. A logical calculus of the ideas immanent in nervous activity. Bull Math Biophys. 1943;5:115-133.

17. Gurney K. An Introduction to Neural Networks. London: Routledge. 1997.

18. Seidel R, Mayr M, Schäfer F, et al. Towards a Smart Electronics Production Using Machine Learning Techniques. 42nd International Spring Seminar on Electronics Technology (ISSE). Wroclaw, Poland. 2019:1-6.

19. Hegde J, Rokseth B. Applications of machine learning methods for engineering risk assessment-A review. Safety Science. 2020;122:104492.

20. $\mathrm{Pu} \mathrm{Y,} \mathrm{Apel} \mathrm{DB,} \mathrm{Liu} \mathrm{V,} \mathrm{et} \mathrm{al.} \mathrm{Machine} \mathrm{learning} \mathrm{methods} \mathrm{for} \mathrm{rockburst}$ prediction-state-of-the-art review. International Journal of Mining Science and Technology. 2019;29:4.

21. Ren Q, Wang G, Li M, et al. Prediction of Rock Compressive Strength Using Machine Learning Algorithms Based on Spectrum Analysis. Geotech Geol Eng. 2019;37:475-489.
22. Balasis G, Aminalragia-Giamini S, Papadimitriou C, et al. A machine learning approach for automated ULF wave recognition. J Space Weather Space Clim. 2019:9.

23. Muggleton SH, Lin D, Pahlavi N, et al. Meta-interpretive learning application to grammatical inference. Machine Learning. 2014;94:2549.

24. Handels H, Rob T, Kreusch J, et al. A feature selection for optimized skin tumor recognition using genetic algorithms. Artif Intell Med. 1999; 16:283-297.

25. Gniadecka M, Alshede PP, Sigurdsson S, et al. Melanoma diagnosis by Raman spectroscopy and neural networks: structure alterations in proteins and lipids in intact cancer tissue. J Invest Dermatol. 2004;122:443-449.

26. Ming H, Vojislav K. Gene extraction for cancer diagnosis by support vector machines. Artif Intell Med. 2005;35:185-194.

27. Garijo N, Martínez J, García-Aznar JM, et al. Computational evaluation of different numerical tools for the prediction of proximal femur loads from bone morphology. Comput Methods Appl Mech Eng. 2014;268(Supplement C):437-450.

28. Cilla M, Borgiani E, Martínez J, et al. Machine learning techniques for the optimization of joint replacements: application to a short-stem hip implant. PLOS ONE. 2017;12(9):1-16.

29. Santhanam P, Ahima RS. Machine Learning and blood pressure. Journal of Clinical Hypertension. 2019;21(11):1735-1737.

30. Abdar M, Książek W, Acharya UR, et al. A new machine learning technique for an accurate diagnosis of coronary artery disease. Computer Methods and Programs in Biomed. 2019:179.

31. Leiner T, Rueckert D, Suinesiaputra A, et al. Young Machine learning in cardiovascular magnetic resonance: basic concepts and applications. $J$ Cardiovascular Magnetic Resonance. 2019;21(61).

32. Cilla M, Martínez J, Peña E, et al. Machine learning techniques as a helpful tool towards determination of plaque vulnerability. IEEE Trans Biomed Eng. 2012b;9(4):1155-1161.

33. Liang L, Kong F, Martin C, et al. Machine learning-based 3-D geometry reconstruction and modeling of aortic valve deformation using 3-D computed tomography images. Int J Numer Method Biomed Eng. 2017;33(5):e2827.

34. Truesdell C, Noll W. The Non-Linear Field Theories of Mechanics, 3rd edn. Berlin-Heidelberg. Springer-Verlag; 2004 